\title{
Efeito da secagem, do armazenamento e da germinação sobre a micromorfologia de sementes de Eugenia pyriformis Camb. ${ }^{1}$
}

\author{
Cristina Filomena Justo ${ }^{2,6,7}$, Amauri Alves de Alvarenga ${ }^{3}$, Eduardo Alves ${ }^{4}$, Renato Mendes Guimarães ${ }^{5}$ e \\ Rosali Constantino Strassburg ${ }^{6}$
}

Recebido em 9/06/2006. Aceito em 21/11/2006

\begin{abstract}
RESUMO - (Efeito da secagem, do armazenamento e da germinação sobre a micromorfologia de sementes de Eugenia pyriformis Camb.). Eugenia pyriformis Camb. é uma espécie arbórea frutífera de porte mediano, cujos frutos saborosos apresentam sementes grandes de tegumento delgado (cartáceo), as quais perdem rapidamente a viabilidade quando submetidas à dessecação. O objetivo foi investigar a estrutura do embrião das sementes, bem como as alterações ultra-estruturais resultantes de secagem, germinação e armazenamento. O eixo embrionário tem menos de 1,0 mm de comprimento, enquanto os cotilédones carnosos podem variar de $1,0 \mathrm{a} 2,0 \mathrm{~cm}$. $\mathrm{O}$ embrião é maciço, globoso, de cor esbranquiçada e preenche todo o espaço delimitado pelo tegumento. A dessecação das sementes provocou gradativa desestruturação celular, a qual também ocorreu com o envelhecimento das sementes. Durante a germinação, o meristema apical do caule altera-se da forma côncava para a cônica e ocorre alongamento do eixo hipocótilo radicular, com protrusão da raiz. Nessa fase, as células apresentam conteúdo íntegro e hidrólise de reservas. Foi avaliada a variação no conteúdo de água das sementes e discutem-se as conseqüências fisiológicas dessa variação.
\end{abstract}

Palavras-chave: Myrtaceae, uvaia, morfoanatomia de sementes, embrião eugenóide, microscopia eletrônica de varredura, conteúdo de água da semente

\begin{abstract}
The effect of drying, storage and germination on the ultra-structure of Eugenia pyriformis Camb. seeds). Eugenia pyriformis Camb. is a tree species of medium height that produces savory fruits with large thin-coated seeds. These seeds quickly lose viability when submitted to desiccation. Our aim was to investigate embryo structure in E. pyriformis seeds and the ultra-structural changes that result from drying, germination and storage. The axis was less than $1.0 \mathrm{~mm}$ long, while the fleshy cotyledons varied from 1.0 to $2.0 \mathrm{~cm}$. The apical and radicular meristem lie in opposing positions. There is a procambium and a medulla of parenchymatous nature, rich in starch grains. Leafy primordia were identified around the stem meristem and there were unicellular trichomes and stomata on the adaxial epidermis of the cotyledons. The gradual desiccation of the seeds provoked cellular structure disarrangement, which also occurred as the seeds aged. Apical meristem form changed from concave to conical during germination and the radicular hypocotyl axis became elongated, with root protrusion. In this phase, the cells have structured content and hydrolysis of reserves. Seed water content variation was evaluated and the physiological consequences of this change are discussed.
\end{abstract}

Key words: Myrtaceae, seed morpho-anatomy, eugenoid embryo, electron scanning microscopy, seed water content

\section{Introdução}

Diversas espécies do gênero Eugenia produzem frutos saborosos, os quais podem ser consumidos in natura ou na forma de geléias e doces, tendo elevado potencial para a industrialização de sucos. Essas espécies podem também ser utilizadas na recuperação de áreas degradadas, como atrativo para a fauna (Andrade \& Ferreira 2000; Lorenzi 2002). Existem ainda relatos do potencial medicinal contra doenças, como a gota (Schmeda-Hirchmann et al. 1987; Theodoluz et al. 1988).

Eugenia pyriformis Camb. é uma espécie arbórea de porte mediano, ocorrendo naturalmente desde São

\footnotetext{
1 Parte da Tese de Doutorado da primeira Autora

2 Universidade Federal de Mato Grosso, Instituto de Ciências e Letras do Médio Araguaia, Departamento de Ciências Biológicas e da Saúde, 78698-000 Pontal do Araguaia, MT, Brasil

3 Universidade Federal de Lavras, Departamento de Biologia, Setor de Fisiologia Vegetal, C. Postal 3037, 37200-000 Lavras, MG, Brasil

4 Universidade Federal de Lavras, Departamento de Fitopatologia, C. Postal 3037, 37200-000 Lavras, MG, Brasil

5 Universidade Federal de Lavras, Departamento de Agricultura, Setor de Sementes, C. Postal 3037, 37200-000 Lavras, MG, Brasil

6 Universidade do Oeste Paulista, Colegiado de Ciências Biológicas, 85819-670 Cascavel, PR, Brasil

7 Autor para correspondência: cfjusto@uol.com.br
} 
Paulo até o Rio Grande do Sul e, provavelmente, estendendo-se até o Paraguai e a Argentina (Donadio et al. 2002; Lorenzi 2002). Seus frutos maduros são amarelos e têm aroma agradável e sabor adocicado. $\mathrm{O}$ crescimento da árvore é relativamente rápido e sua frutificação é precoce (Andrade \& Ferreira 2000). É conhecida popularmente como uvaia, ubaia e uvalha, derivando da denominação indígena iwa'ya, cujo significado é fruto ácido (Lorenzi 2002; Franzon et al. 2004; Leal 2005). A espécie é resistente a doenças e sua madeira dura tem sido empregada regionalmente para mourões, estacas, postes, lenha e carvão. Os frutos são amplamente consumidos por várias espécies de pássaros, o que torna a espécie recomendável para o reflorestamento de áreas degradadas (Lorenzi 2002).

Donadio et al. (2002) citam a existência de duas variedades: E. pyriformis var. uvalha e E. pyriformis var. argentea, que recebem o mesmo nome popular. No entanto, nem todos os autores reconhecem essa identificação taxonômica e tratam-nas como duas espécies individualizadas: E. pyriformis e E. uvalha Cambess. (Costa 2004; Scalon 2004). Existe ainda a sinonímia botânica Pseudomyrcianthes pyriformis (Camb.) Kaus (Andrade \& Ferreira 2000; Lorenzi 2002).

A anatomia das sementes de Myrtaceae tem sido investigada com alguma ênfase para espécies de importância econômica. Prakash (1979) realizou uma revisão de trabalhos mais antigos a esse respeito, tendo obtido seis publicações dedicadas ao gênero Eugenia. Landrum \& Stevenson (1986), estudaram a estrutura do embrião na subtribo Myrtinae, na qual predominam sementes pequenas com eixo embrionário volumoso e rico em reservas. Segundo Barroso (2002), o embrião no gênero Eugenia é globoso, sem diferenciação aparente entre o eixo embrionário e os cotilédones; além disso, considera-se o embrião conferruminado, ou seja, sem distinção da linha de soldadura entre os cotilédones. Estudos anatômicos das sementes maduras de Eugenia punicifolia (Kunt) DC. revelaram que os cotilédones são maiores do que o eixo embrionário na razão de 3:1 (R.C. Strassburg, dados não publicados).

No gênero Eugenia, geralmente, as sementes são grandes com tegumento delgado e perdem rapidamente a viabilidade quando submetidas à dessecação (Goldbach 1979; Bulow et al. 1994; Andrade \& Ferreira 2000; Salomão \& Santos 2000; Andrade et al. 2003; Maluf et al. 2003; Delgado 2006). Por esta razão, recomenda-se a semeadura imediatamente após a retirada dos frutos (Silva et al. 2001; Lorenzi 2002), dificultando, dessa maneira, a produção de mudas pelo curto período de disponibilidade das sementes (Lorenzi 2002; Silva et al. 2003). Sementes recalcitrantes não toleram a perda de água e sofrem danos em diferentes níveis durante a secagem e o armazenamento (Pammenter et al. 1984), estando sujeitas a danos ultraestruturais (Berjak \& Pammenter 2000).

O objetivo do presente trabalho é investigar anatomicamente a semente de E. pyriformis e avaliar as alterações ultra-estruturais resultantes da secagem, do armazenamento e da germinação.

\section{Material e métodos}

Sementes utilizadas nesta pesquisa foram obtidas de frutos coletados de três matrizes adjacentes, localizadas na área urbana do município de Lavras,

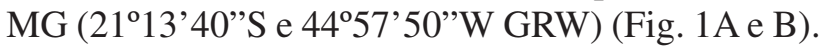
Uma amostra de material com flores (Fig. 1A) foi depositada no Herbário ESAL, da Universidade Federal de Lavras, sob o número de registro 20468. Os frutos maduros, de coloração amarelo-ouro (Fig. 1C), foram coletados diretamente nas plantas e processados em laboratório no mesmo dia.

As sementes foram submetidas à lavagem sob água corrente para limpeza e remoção dos resíduos da polpa. O excesso de umidade da superfície das sementes foi removido com papel toalha, sendo então submetidas a um dos seguintes tratamentos para obtenção dos embriões, como descritos a seguir:

a. imediatamente após a coleta e limpeza, as sementes foram dissecadas com bisturi, separando-se o eixos embrionários e segmentos de cotilédones;

b. após três e 10 dias de embebição em rolo de papel Germitest ${ }^{\circledR}$ e mantidas em câmara de germinação do tipo Mangelsdorff a $25^{\circ} \mathrm{C}$ no escuro;

c. após secagem durante 16 e 72 horas de secagem, sob duas condições de secagem: a $35^{\circ} \mathrm{C}$ em estufa ventilada com $20 \%$ de umidade relativa (UR) e a $20{ }^{\circ} \mathrm{C}$ em sala climatizada com $60 \%$ UR;

d. após armazenamento em embalagens de polietileno, a $10{ }^{\circ} \mathrm{C}$, por sete meses com posterior embebição de 3 dias nas mesmas condições de germinação.

Os embriões, assim obtidos, foram seccionados em pequenas peças e fixados em Karnovisky modificado: glutaraldeído $(2,5 \%)$ e paraformaldeído (2,5\%) em tampão cacodilato 0,05 M, pH 7,2 e $\mathrm{CaCl}_{2}$ 0,001 M (Karnovsky, 1965), sendo mantidos em geladeira a $10{ }^{\circ} \mathrm{C}$, até o posterior processamento; o fixador foi trocado após 10 dias devido à oxidação por 
fenóis originados na amostra. As amostras foram preparadas de acordo com o protocolo padrão do Laboratório de Microscopia Eletrônica e Análise UltraEstrutural (LME) do Departamento de Fitopatologia da Universidade Federal de Lavras, para isso foram lavadas três vezes em tampão cacodilato $0,05 \mathrm{M}$, durante 10 minutos e imersas em glicerol 30\%, como crioprotetor, durante 30 minutos. Após congelamento em $\mathrm{N}_{2}$ líquido, as amostras foram cortadas com bisturi em superfície resfriada para expor os tecidos internos da semente. O eixo embrionário foi seccionado longitudinalmente em nitrogênio líquido para observação ao microscópio eletrônico de varredura, usando o ápice da radícula como referência (Fig. 1E e 2A).

O material seccionado foi lavado em $\mathrm{H}_{2} \mathrm{O}$ destilada e pós-fixado com tetróxido de ósmio (1\%) durante $4 \mathrm{~h}$ à temperatura ambiente em capela, sendo lavado três vezes com $\mathrm{H}_{2} \mathrm{O}$ destilada durante 5 minutos e submetido à desidratação em gradiente crescente de acetona $(25,50,75$ e $90 \%)$ durante $15 \mathrm{~min}$ em cada solução e três vezes em acetona pura. As amostras foram levadas para secagem ao ponto crítico com $\mathrm{CO}_{2}$ líquido no aparelho CPD 030 (Balzers), sendo então montadas em "stubs". A seguir receberam uma cobertura de ouro no evaporador SCD 050 (Balzers). A análise foi realizada em microscópio eletrônico de varredura modelo Leo Evo 40, com a obtenção de imagens digitais pelo software Leo User Interface (Alves 2004).

Determinou-se gravimetricamente o teor de água das sementes em todos os tratamentos utilizando-se cinco repetições de sementes individuais, o qual foi expresso em percentagem em relação à massa fresca. Para tanto, as sementes foram pesadas e secas em estufa, a $105^{\circ} \mathrm{C}$, durante $48 \mathrm{~h}$ (adaptado de Brasil 1992).

O teor de água das sementes, durante a secagem e a embebição, foi analisado por regressão linear em função do tempo, considerando para o tempo zero, o conteúdo de água das sementes recém-colhidas. No teste de secagem, os dados foram analisados em esquema fatorial $(2 \times 2)$ em DIC, considerando como fontes de variação a temperatura e o tempo de secagem, sendo as médias comparadas pelo teste de Tukey a 5\% de probabilidade. Utilizou-se a comparação por contraste entre os tamanhos de sementes, entre as sementes embebidas e recém-colhidas e entre as armazenadas e os demais tratamentos. Para análise estatística, foi utilizado o software SISVAR, versão 4.6 (Santana \& Ranal 2000; Ferreira 2003).

\section{Resultados e discussão}

$\mathrm{O}$ fruto maduro é uma baga de cor amarela (Fig. 1B), com mesocarpo carnoso (Fig. 1C). O número de sementes por fruto é variável, geralmente não excedendo a quatro, no entanto, elas são menores quando mais numerosas.

A semente é exalbuminosa, de formato elíptico irregular, variando de globoso a semigloboso; seu maior comprimento varia entre 0,5 e $2,0 \mathrm{~cm}$ e a massa de sementes frescas entre 0,5 e 2,5 g. O embrião é maciço, globoso, de cor esbranquiçada e preenche todo o espaço delimitado pelo tegumento (Fig. 1C). Os cotilédones são carnosos, retos e rugosos (Fig. 1D, E).

Em E. pyriformis, o tegumento das sementes é delgado, de cor marrom variegada e de textura cartácea (Fig. 1C, D). A rafe destaca-se pela cor ligeiramente mais pálida do que o restante do tegumento, estendendo-se sobre a face convexa da superfície da semente. A protrusão da raiz pode ser observada na extremidade da rafe (Fig. 1F). Segundo Andrade et al. (2003), em sementes de E. dysenterica, a cor mais clara da rafe deve-se ao fato do tegumento ter apenas uma camada nessa região, já no restante da semente, ele é formado por duas camadas. Além disso, nessa espécie, a rafe é bem mais conspícua do que nas sementes de E. pyriformis (Lorenzi 2002). Strassburg (dados não publicados) observou, em $E$. punicifolia, que apenas a testa permanece na semente madura, ocorrendo desintegração do tégmen ao longo do desenvolvimento da semente.

Rizzini (1970) observou uma diferença marcante na estrutura da testa de duas espécies de Eugenia. Para E. dsysenterica, espécie de cerrado, ela é coriácea e em E. micheli (sinonímia de E. uniflora L., pitanga), é mais delgada e membranácea. $\mathrm{O}$ autor observou nítido contraste no poder germinativo provocado pela diversidade de tegumento das duas espécies. A espessura do tegumento varia bastante entre espécies de Eugenia africanas, ocorrendo graus variáveis de esclerificação e vascularização do mesmo (van Wyk \& Botha 1984).

O eixo embrionário não se distingue no embrião a olho nu, no entanto, com uma lupa de pequeno aumento foi possível visualizar o pólo embrionário em uma das extremidades da cicatriz rafeal na superfície dos cotilédones. Nessa posição, o ápice da radícula é formado por uma pequena protuberância, sendo rodeada por uma depressão circular de cor ligeiramente diferente do restante do embrião (Fig. 1E). Esta protuberância apresenta cerca de $400 \mu \mathrm{m}$ de diâmetro, 
quando observada ao microscópio eletrônico de varredura (Fig. 2A).

A observação do eixo embrionário ao microscópio eletrônico de varredura mostra que ele é reto, completamente formado e tem cerca de $800 \mu \mathrm{m}$ de comprimento (Fig. 2B), com pólo apical e radicular em seus extremos (Fig. 2C e 2D). Estes pólos são constituídos por células pequenas, com características meristemáticas (Fig. 2C e 2D), sendo ainda possível visualizar o procâmbio, formado por células mais alongadas do que as demais (Fig. 2E).

Barroso (2002) afirma que o embrião nas sementes do gênero Eugenia é globoso, crasso, conferruminado e sem diferenciação aparente entre o
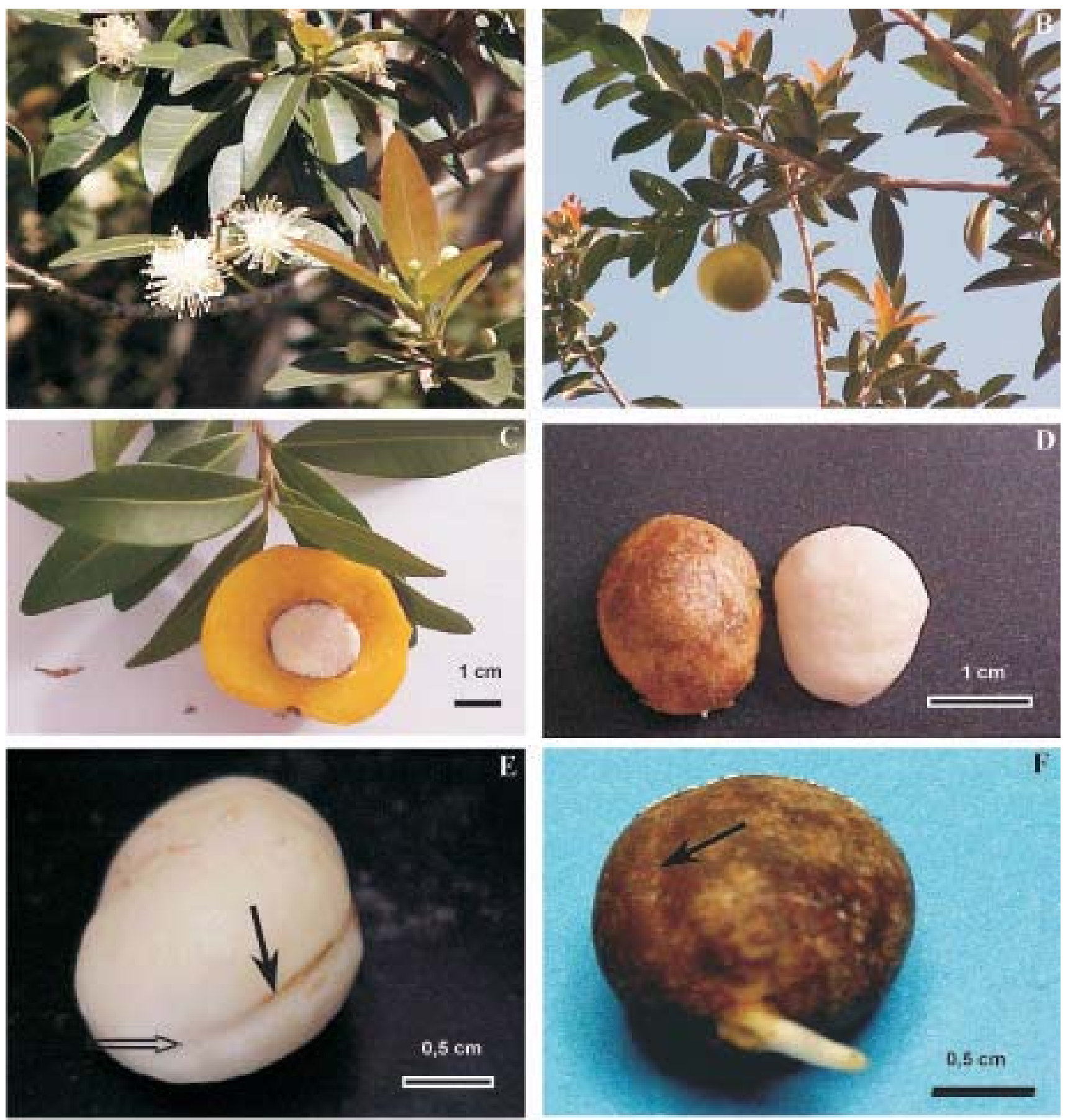

Figura 1. Aspectos gerais de Eugenia pyriformis Camb. A. Ramo com flores. B. Ramo com fruto. C. Fruto e semente cortados longitudinalmente. D. Semente com e sem tegumento cortada ao longo da rafe. E. Semente recém colhida sem tegumento, com destaque para o pólo radicular (seta vazia) e cicatriz rafeal na superfície dos cotilédones (seta cheia). F. Semente germinada com destaque para a rafe no tegumento (seta). 

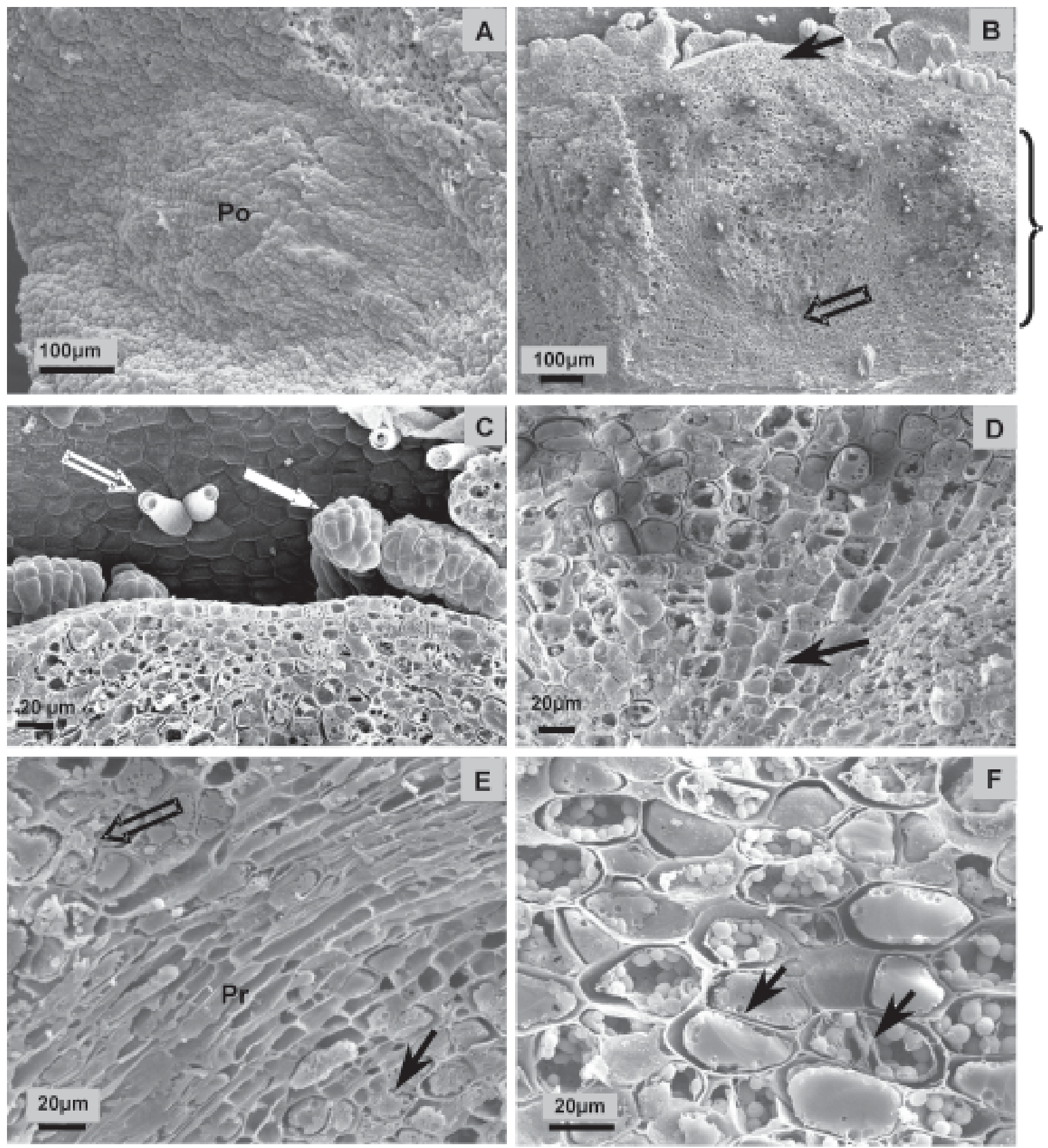

Figura 2. Eletromicrografias de varredura do eixo embrionário de sementes recém colhidas de Eugenia pyriformis Camb. A. Visão da superfície da semente na região do pólo radicular, formando uma protuberância semi-esférica rodeada por uma depressão circular. B. Visão geral do eixo embrionário em corte longitudinal, com destaque para a ampla região de conexão entre o eixo e os cotilédones (chave à direita) e meristema apical do caule (seta cheia) e da radícula (seta vazia). C. Meristema apical do caule, circundado por primórdios foliares (seta cheia) e tricomas (seta vazia). D. Meristema apical da radícula (seta). E. Procâmbio ladeado pelo meristema fundamental do eixo embrionário (seta cheia) e pelo tecido de conexão ao cotilédone (seta vazia). F. Medula do eixo embrionário com células ricas em grãos de amido e indícios de mitose recente (setas). (B a F) Seções longitudinais obtidas por corte em nitrogênio líquido $\left(-186^{\circ} \mathrm{C}\right)$. Po = pólo radicular, $\operatorname{Pr}=$ procâmbio. 
eixo radícula-hipocótilo e os cotilédones. Outros autores afirmam que não há diferenciação entre o eixo embrionário e os cotilédones (Andrade \& Ferreira 2000; Lucas et al. 2005). O presente estudo contradiz as afirmações de Andrade \& Ferreira (2000) e Lucas et al. (2005), uma vez que o eixo embrionário encontra-se diferenciado na semente madura, porém não está visível na superfície da semente devido ao fato de estar parcialmente encoberto por tecido, o qual foi interpretado como a região de conexão entre o eixo e os cotilédones (Fig. 2B, chave à direita).

Em algumas espécies de Eucalyptus L'Herit. e Syzygium Gaertn., observa-se o recobrimento do hipocótilo e da raiz primária pelos cotilédones, levando a uma interpretação errônea de fusão entre os tecidos. Para distinguir esse fenômeno, Kausel (1956), citado por Landrum \& Stevenson 1986), propôs a subfamília Cryptorhizeae, utilizando como critério o recobrimento do hipocótilo e da raiz primária pelos cotilédones, mas esse táxon é aceito por alguns autores, mas não por outros. No entanto, essa subfamília não inclui o gênero Eugenia.

Em sementes imaturas retiradas de frutos verdes, antes do desenvolvimento total dos cotilédones, o eixo hipocótilo-radicular é perfeitamente distinto, formando uma protuberância cônica de cerca de $1,0 \mathrm{~mm}$ de comprimento (Justo, dados não publicados). Situação similar foi observada por Strassburg (dados não publicados) em E. punicifolia, onde a autora descreve a existência de grandes diferenças entre o embrião na fase jovem e madura.

A medula do eixo embrionário é constituída por células relativamente grandes $(40 \mu \mathrm{m})$, com paredes delgadas e ricas em grãos de amido (Fig. 2F). Apesar dos volumosos cotilédones, talvez essas reservas sejam consumidas primeiramente durante o alongamento do eixo embrionário na germinação de E. pyriformis, devido à sua proximidade com os tecidos em desenvolvimento. Em espécies da tribo Myrtinae (Pimenta spp., Blepharocalyx spp. e Campomanesia adamantium (Camb.) O. Berg), o hipocótilo volumoso é a principal fonte de reservas para a plântula, sendo o amido, o componente majoritário dessas reservas (Landrum \& Stevenson 1986), enquanto espécies africanas de Eugenia apresentam cotilédones ricos em amido (van Wyk \& Botha 1984). Nas sementes de E. pyriformis sem tegumento, cerca de $70 \%$ da matéria seca é composta por amido (N. Delú Filho, comunicação pessoal).

Projeções multicelulares observadas adjacentes ao meristema apical foram interpretadas como primórdios foliares (Fig. 3A), embora na plântula de $E$. dysenterica, estruturas similares tenham sido denominadas catáfilos (Andrade et al. 2003). Catafilos geralmente ocorrem em rizomas e bulbos, são folhas sésseis que podem ter função de reserva (Modesto \& Siqueira 1981). Para sementes e plântulas, o termo é citado por Fahn (1982) para Vicia faba, pois os primórdios presentes na gema apical da semente não se expandem. Talvez sejam necessários mais estudos para esclarecer a ontogenia dessas estruturas em $E$. pyriformis, pois no estágio analisado neste trabalho, o desenvolvimento do epicótilo ainda é muito incipiente (Fig. 3D e 3E).

A olho nu, a face adaxial dos cotilédones é lisa nas sementes de E. pyriformis, enquanto a face abaxial é rugosa (Fig 1D). A linha de soldadura é pouco conspícua, mas há uma epiderme definida na face adaxial dos mesmos (Fig. 3B, C). Nesta epiderme, foi possível observar a presença de tricomas unicelulares e estômatos; as demais células apresentam forma poligonal irregular e dimensões de cerca de $20 \mu \mathrm{m}$ (Fig. 3C). A partir das observações realizadas, conclui-se que a fusão cotiledonar é mínima e está restrita às proximidades do eixo embrionário, na região que foi interpretada como conexão entre o eixo e os cotolédones. Em E. punicifolia e E. hiemalis, observa-se sincotilia parcial (Strassburg, dados não publicados). O embrião de E. stipitata ssp. sorosia é classificado como pseudomonocotiledonar, devido à fusão total ou parcial dos cotilédones (Anjos \& Ferraz 1999). Em espécies africanas de Eugenia, a fusão dos cotilédones é extensa (van Wyk \& Botha 1984). Segundo Barroso (2002), a fusão dos cotilédones é tal que não permite a distinção da linha de soldadura entre eles, sendo esta característica de soldadura utilizada como critério para a separação entre Eugenia e Syzigium (Schmid 1972). Estudos de seqüenciamento de DNA mostraram que esses dois gêneros não são estreitamente aparentados e a ocorrência de frutos carnosos em ambos provavelmente resulta de evolução paralela (Lucas et al. 2005).

Em E. pyriformis, o eixo embrionário na semente madura tem menos de 1,0 mm (Fig. 2B), enquanto os cotilédones são proporcionalmente maiores, na razão de 10:1 ou mais, podendo apresentar de 1,0 a $2,0 \mathrm{~cm}$ de comprimento (Fig. 1D). Nas sementes em desenvolvimento de E. punicifolia, o eixo embrionário é mais longo que os cotilédones, enquanto na semente madura a relação se inverte devido à deposição de reservas nos cotilédones, os quais se tornam volumosos na razão de 3:1 em relação ao eixo (Strassburg, dados 

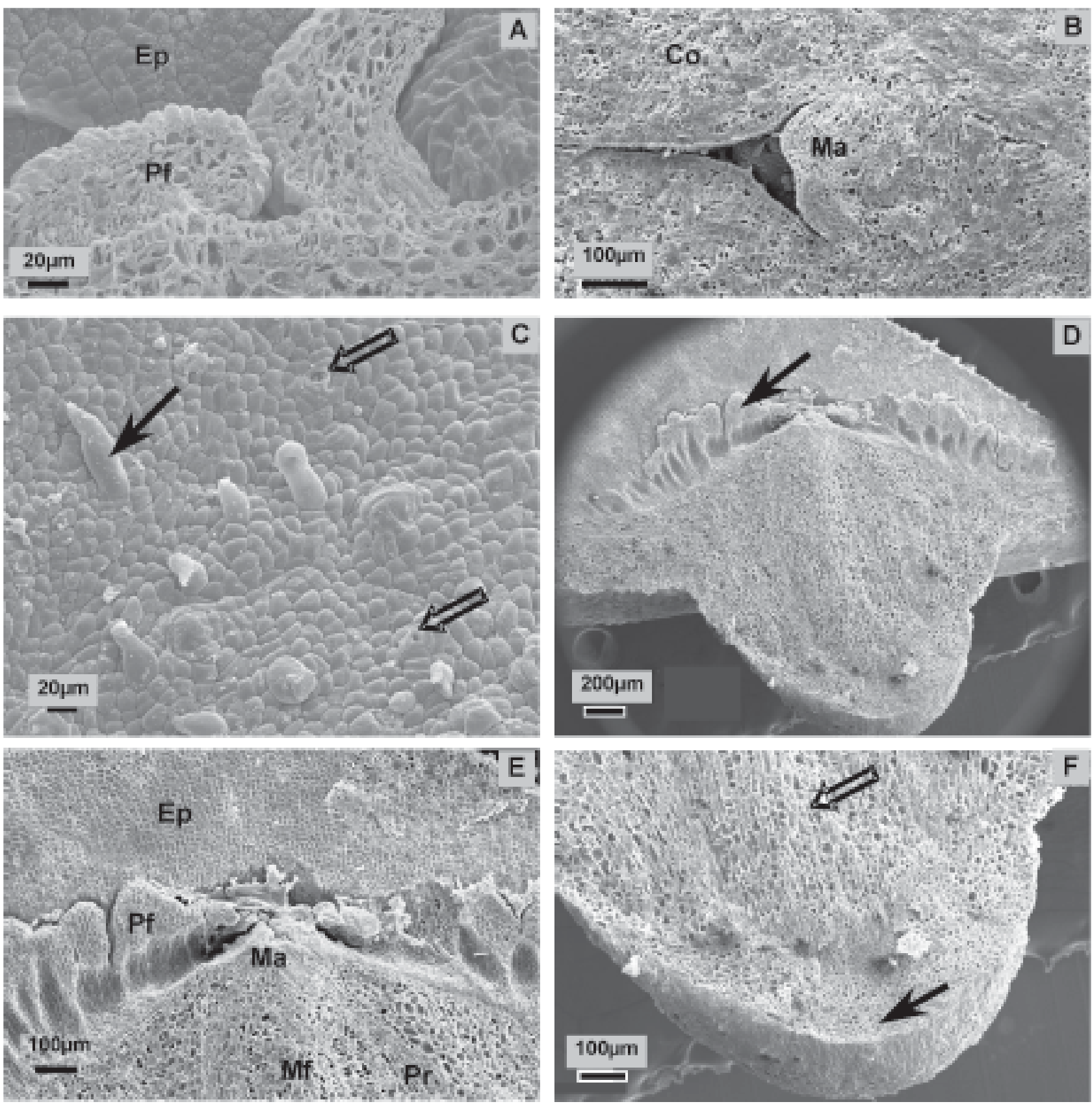

Figura 3. Eletromicrografias de varredura de sementes de Eugenia pyriformis Camb. A. Detalhe de primórdios foliares em corte longitudinal. B. Meristema apical do eixo embrionário e cotilédones em corte, mostrando continuidade entre o eixo embrionário e os cotilédones. C. Detalhe da epiderme adaxial cotiledonar em vista frontal, com destaque para tricoma unicelular (seta cheia) e estômatos (setas vazias). D. Visão geral do eixo embrionário de semente germinando após 10 dias de embebição a $25^{\circ} \mathrm{C}$, com destaque para os primórdios foliares (seta). E. Meristema apical de semente germinada, com alteração para forma cônica (comparar com a figura 2C). F. Detalhe do ápice da raiz após protrusão, com destaque para a coifa (seta cheia) e o cilindro vascular (seta vazia). (A-B, C-F) Seções longitudinais obtidas por corte em nitrogênio líquido $\left(-186^{\circ} \mathrm{C}\right) . \mathrm{Co}=$ cotilédone, $\mathrm{Ep}=$ epiderme adaxial do cotilédone, $\mathrm{Ma}=$ meristema apical do caule, $\mathrm{Mf}=$ meristema fundamental medular, $\mathrm{Pf}=$ primórdio foliar, $\mathrm{Pr}=$ procâmbio. 
não publicados). Segundo Barroso (2002) e Landrum \& Stevenson (1986), na subtribo Eugeniinae (Calycorectes, Eugenia e Siphoneugena) ocorrem os cotilédones carnosos; nas Myrtinae (Campomanesia e Psidium), são vestigiais e nas Myrciinae (Calyptranthes, Gomidesia e Myrcia), são folhosos e mais largos em relação ao hipocótilo.

Nas sementes recém-colhidas, as células de ambos os meristemas apicais são pequenas (20 $\mu$ m ou menos), não sendo observados grãos de amido nestas regiões (Fig. 2B, C e D). Em algumas células da medula do eixo embrionário, o citoplasma é denso, no entanto nas células ricas em amido, o citoplasma é periférico, indicando vacuolização (Fig. 2F). Segundo Pammenter \& Berjak (1999), tal característica é típica de sementes recalcitrantes e representa uma limitação à tolerância à dessecação, pois durante a secagem, pode ocorrer stress mecânico sobre as células.

Observaram-se, ainda, sinais de mitose recente na região medular do eixo embrionário (Fig. 2F), indicando metabolismo ativo das sementes maduras. Em outras espécies recalcitrantes, a respiração celular é mensurável em sementes recém-colhidas (Pammenter \& Berjak 1999) e o metabolismo dessas sementes mantém-se ativo para conteúdo de água superior a $0,25 \mathrm{~g} \mathrm{H}_{2} \mathrm{O} . \mathrm{g}^{-1}$ matéria seca (MS), ou seja, cerca de $20 \%$ de umidade (Vertucci \& Leopold 1984; Vertucci 1989). No presente estudo, todos os tratamentos encontravam-se acima desse limite, exceto as sementes armazenadas antes da embebição (Tab. 1 e 2).

Nas sementes germinadas, observaram-se ainda grandes alterações morfológicas em comparação às sementes recém colhidas (Fig. 2B e 3D). O meristema apical do caule alterou-se da forma convexa para a cônica e os primórdios foliares da forma alongada para achatada, indicando expansão lateral dos mesmos (Fig. 2C e 3E). Houve alongamento da radícula

Tabela 1. Conteúdo de água (\%) das sementes de Eugenia pyriformis $\mathrm{Camb}$. submetidas à secagem durante diferentes períodos de tempos e temperaturas. $\mathrm{N}=5$ repetições de sementes individuais por tratamento.

\begin{tabular}{cccc}
\hline \multirow{2}{*}{$\begin{array}{c}\text { Temperatura } \\
\text { de secagem }\left({ }^{\circ} \mathrm{C}\right)\end{array}$} & \multicolumn{2}{c}{ Tempo de secagem (horas)* } & \multirow{2}{*}{ Médias } \\
\cline { 2 - 3 } & 16 & 72 & \\
\hline 20 & $48,58 \pm 1,71 \mathrm{aA}$ & $46,68 \pm 2,75 \mathrm{aA}$ & $47,63 \mathrm{~A}$ \\
35 & $45,89 \pm 1,62 \mathrm{aA}$ & $30,64 \pm 6,64 \mathrm{bB}$ & $38,27 \mathrm{~B}$ \\
Médias & $47,23 \mathrm{a}$ & $38,66 \mathrm{~b}$ & 42,95 \\
\hline
\end{tabular}

* Médias \pm desvio padrão. Médias seguidas da mesma letra minúscula na linha e maiúscula na coluna não diferem estatisticamente entre si, pelo teste de Tukey, a $5 \%$ de probabilidade.
(Fig. 3D), na qual foi possível observar a coifa e o cilindro vascular em diferenciação (Fig. 3F).

Para comparação entre os tratamentos, procurouse observar a mesma região em todas as amostras (Fig. 4), pois segundo Berjak \& Pammenter (2000), ocorrem diferenças ultra-estruturais entre tecidos da mesma semente, indicando seus respectivos estados metabólicos.

Em comparação ao material fresco (Fig. 4A), ocorreu progressiva desestruturação do conteúdo citoplasmático nas células do meristema fundamental das sementes submetidas à secagem (Fig. 4B). Estas alterações foram mais intensas na secagem a $35{ }^{\circ} \mathrm{C}$ durante 72 horas, embora a perda de água não tenha sido letal até esse nível (Tab. 1; Justo et al., dados não publicados). Os grãos de amido permaneceram visíveis, mas observaram-se alterações no citoplasma (Fig. 4B) e, possivelmente, houve descompartimentação celular em função da secagem.

Berjak \& Pammenter (2000) enfatizam que eventos com efeitos sobre a arquitetura intracelular podem ter profundas conseqüências sobre o funcionamento da célula, pois o citoesqueleto é uma estrutura tridimensional dinâmica, responsável pela manutenção das posições intracelulares das organelas umas em relação às outras. Portanto, a desorganização do citoesqueleto pode tornar a célula não funcional no caso do dano não poder ser reparado.

A secagem branda pode estimular o metabolismo da semente com respostas ultra-estruturais similares à diferenciação celular que ocorre durante a germinação. Segundo Berjak et al. (1984), esse nível de secagem estimulou o desenvolvimento mitocondrial, indicando um aumento da respiração celular, contudo, no presente estudo, não foi possível observar tais organelas.

Nas sementes em fase de germinação, foi possível observar cordões de citoplasma ao redor dos grãos de amido, possivelmente devido ao início da hidrólise das reservas durante a embebição (Fig. 4C).

O conteúdo citoplasmático estava completamente desintegrado nas células das sementes armazenadas (sete meses), embora os grãos de amido ainda estivessem presentes (Fig. 4D). Aparentemente não houve hidrólise do amido durante esse período. Os cotilédones apresentavam coloração marrom, mas não havia sinais de deterioração por fungos. Estas sementes foram armazenadas com seu conteúdo inicial de água, mas perderam umidade durante o armazenamento, endurecendo-se e foi necessário embebê-las antes da excisão dos eixos embrionários (Tab. 2). 
Tabela 2. Conteúdo de água das sementes de Eugenia pyriformis Camb. submetidas a diferentes tratamentos. $\mathrm{N}=5$ repetições de sementes individuais por tratamento.

Tratamento

Conteúdo de água

$(\%)$

Recém colhidas*

Sementes pequenas

Sementes grandes

Embebição a $25^{\circ} \mathrm{C}$

(horas)

72

240

Armazenamento ${ }^{\circledR}$

Antes da embebição

Após a embebição ${ }^{*}$
$55,09 \pm 3,43$

$57,09 \pm 2,36^{8}$

$50,10 \pm 1,99$

$53,82 \pm 2,03$

$6,96^{\$}$

$53,77 \pm 4,85$
Contrastes

Recém-colhidas

Pequenas versus Grandes

NS

Embebidas 72 horas versus 240 hora Embebidas versus Recém-colhidas

NS

**

NS

NS

* = Tamanho definido de acordo com o diâmetro das sementes: Pequenas = 0,5-0,9 cm, Grandes = 1,0-2,0 cm; $\S=$ Sementes Germinadas, com 2-5 mm de protrusão de radícula; @ = armazenamento em embalagem plástica semi-permeável (polietileno) durante sete meses a $10{ }^{\circ} \mathrm{C}$; $\$=$ Amostra sem repetição; \& = Embebição a $25{ }^{\circ} \mathrm{C}$ durante 72 horas, em papel Germitest ${ }^{\circ}$, umedecido com água destilada; NS = não significativo, $* *=$ significativo a $1 \%$ de probabilidade.
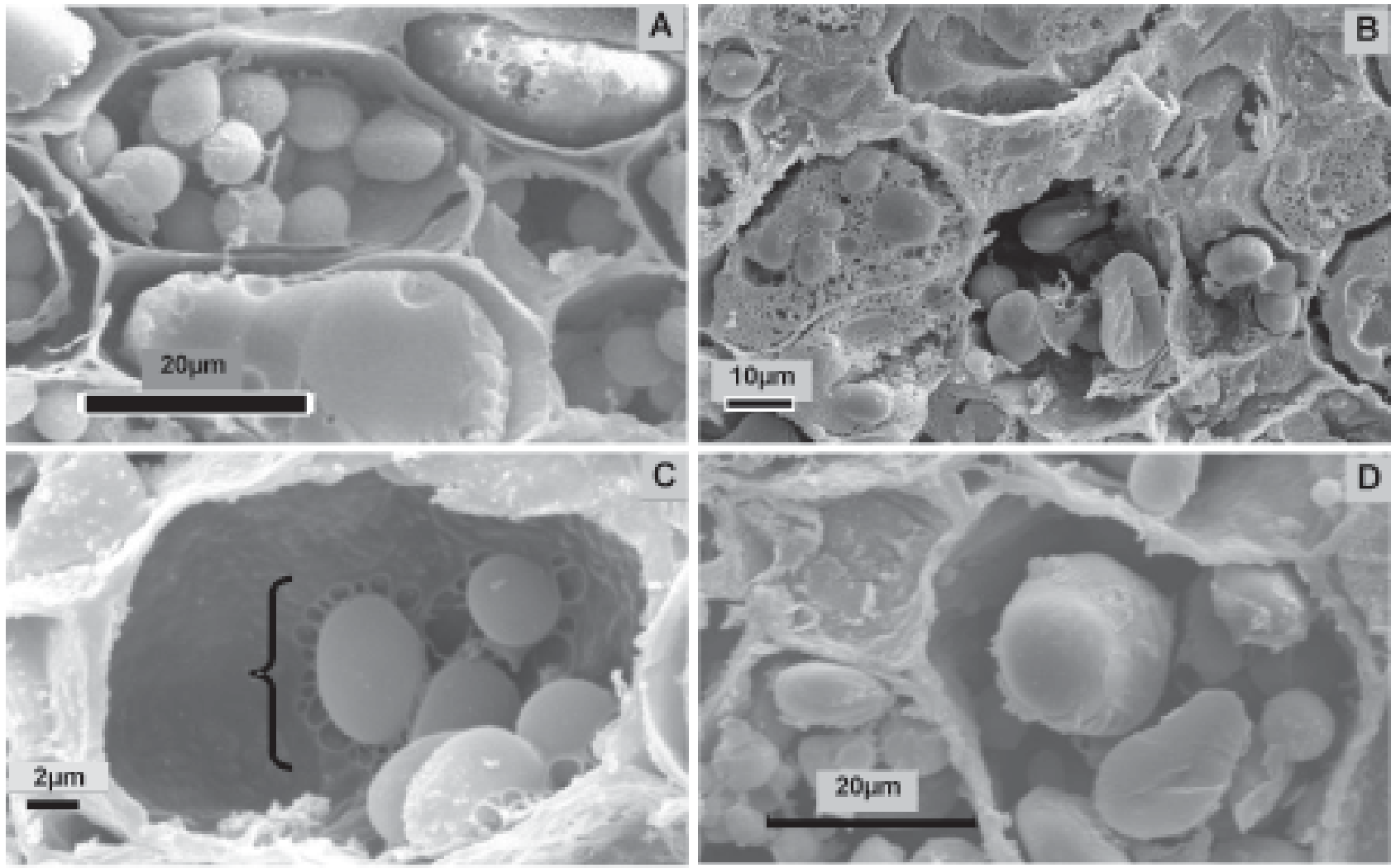

Figura 4. Eletromicrografias de varredura de células do meristema fundamental da região de conexão entre o eixo embrionário e os cotilédones de sementes de Eugenia pyriformis Camb. submetidas a diferentes tratamentos. A. Sementes recém-colhidas. B. Sementes dessecadas durante $72 \mathrm{~h}$ a $35^{\circ} \mathrm{C}$, com destaque para citoplasma alveolado ao redor dos grãos de amido. C. Sementes embebidas durante três dias a $25^{\circ} \mathrm{C}$, com destaque para os cordões de citoplasma ao redor dos grãos de amido (chave à esquerda). D. Sementes armazenadas durante sete meses a $10^{\circ} \mathrm{C}$ e embebidas por três dias, a $25^{\circ} \mathrm{C}$, antes da coleta de amostra. Notar desagregação do citoplasma. 
Talvez a perda de viabilidade das sementes armazenadas de E. pyriformis esteja relacionada com processos endógenos de envelhecimento. Segundo Kranner \& Birtic (2005), a falha dos sistemas antioxidantes causam envelhecimento, dando início ao processo de morte celular programada, as autoras sugerem que os mecanismos antioxidantes são fundamentais para a tolerância à dessecação. $\mathrm{O}$ presente trabalho, no entanto, não permitiu a elucidação do mecanismo exato da deterioração das sementes de E. pyriformis.

Scalon et al. (2004), avaliando o desempenho germinativo em sementes de E. uvalha armazenadas por 120 dias em duas condições ambientais, observaram maior longevidade à temperatura mais baixa $\left(10{ }^{\circ} \mathrm{C}\right)$, com perda progressiva de viabilidade mesmo nessa condição. Segundo Pammenter et al. (1984), o metabolismo não é interrompido durante o armazenamento de sementes recalcitrantes, podendo apresentar diferenciação celular similar à que ocorre durante a germinação. O trabalho de Farrant et al. (1986) confirma essas observações, pois as sementes de Avicennia marina (Forsk) Vierh. tornam-se progressivamente sensíveis à medida que os processos germinativos ocorrem, mesmo durante o armazenamento.

No que diz respeito ao conteúdo de água, as sementes recém colhidas continham cerca de $50 \%$, notando-se pequena variação entre sementes grandes e pequenas (Tab. 2). A secagem das sementes resultou em redução do conteúdo de água de acordo com o tempo de secagem e a temperatura. A maior perda de água foi observada a $35^{\circ} \mathrm{C}$ e 72 horas de secagem (Tab. 1). Embora esse conteúdo de água (30\%) esteja acima do limite letal para as sementes, a secagem até esse nível reduz significativamente a velocidade de germinação das sementes (Justo et al., dados não publicados). Resultados similares foram obtidos por Andrade e Ferreira (2000) para sementes de E. pyriformis armazenadas a $5^{\circ} \mathrm{C}$ e a $15^{\circ} \mathrm{C}$, com decréscimo da emergência para um teor de umidade inferior a $20 \%$ e perda total de viabilidade para conteúdo de água de $14 \%$, indicando o caráter recalcitrante dessas sementes.

Nos tratamentos de secagem mais branda (16 e 72 horas, a $20^{\circ} \mathrm{C}$ e 16 horas, a $35{ }^{\circ} \mathrm{C}$ ), o conteúdo de água das sementes reduziu-se pouco em relação ao conteúdo inicial (Tab. 1 e 2) e os danos ultra-estruturais foram menores em comparação à secagem por 72 horas, a $35^{\circ} \mathrm{C}$ (Fig. 5).

Em conteúdos intermediários de água (entre 25 e $45 \%$ ), o metabolismo pode estar desregulado e existem evidências de danos causados por reações químicas envolvendo radicais livres (Leprince et al. 1990; 1992; Hendry et al. 1992; Hendry 1993; Finch-Savage et al. 1994; Vertucci \& Farrant 1995), os quais contribuem para a peroxidação de lipídeos (Hendry et al. 1992). Tommasi et al. (1999), estudando os mecanismos antioxidantes em sementes recalcitrantes e ortodoxas, observaram grandes diferenças entre estas duas classes: o conteúdo de ácido ascórbico é mais elevado nas recalcitrantes em relação às ortodoxas, porém o sistema enzimático de regeneração do ácido ascórbico é mais eficiente nas sementes ortodoxas.

Os mecanismos antioxidantes desempenham um importante papel na aquisição da tolerância à dessecação das sementes em desenvolvimento e na armazenabilidade (Bailly 2004). A perda de viabilidade
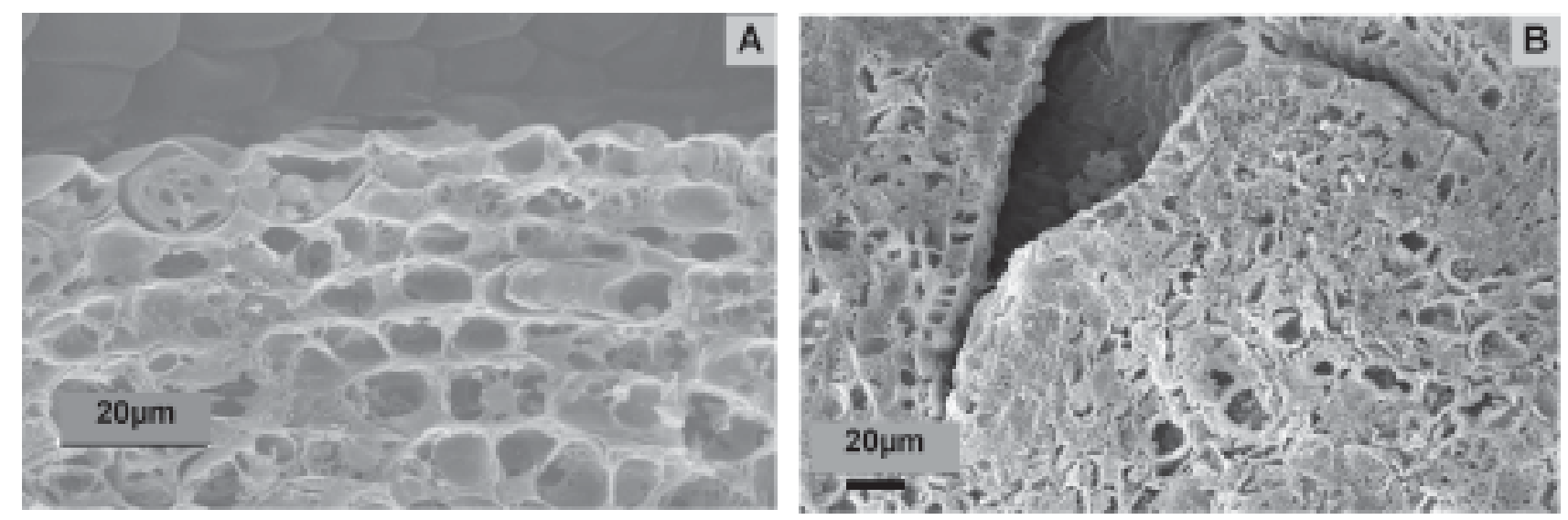

Figura 5. Eletromicrografias de varredura dos meristemas apicais do eixo embrionário de sementes de Eugenia pyriformis Camb. submetidas a diferentes tratamentos de secagem. A. Secagem branda durante 16 horas a $35^{\circ} \mathrm{C}$ com poucos danos ultra-estruturais. B. Secagem intensa durante 72 horas a $35^{\circ} \mathrm{C}$, com danos ultra-estruturais significativos. 
durante a secagem está relacionada com a falha desses mecanismos (Finch-Savage et al. 1994). Os compostos fenólicos têm propriedades anti-oxidantes in vitro (Rice-Evans et al. 1996), todavia o papel desses compostos como antioxidantes citoplasmáticos ainda é incerto (Kranner \& Birtic 2005). As sementes de Theobroma cacao L., embora ricas em compostos fenólicos (Niemenak et al. 2006), apresentam sensibilidade à dessecação (Chandel et al. 1995). As sementes de E. pyriformis também são ricas nesse tipo de compostos (Justo et al., dados não publicados).

Nas sementes embebidas e germinadas, o conteúdo de água aumentou ligeiramente em relação ao conteúdo nas sementes recém colhidas (Tab. 2). Farrant et al. (1986) argumentam que a embebição não é indispensável para a ocorrência de processo germinativo em sementes recalcitrantes. No entanto considerando o conteúdo de água em base seca (Vertucci 1989), observa-se que nas sementes recémcolhidas esse valor era de $1,007 \mathrm{~g} \mathrm{H}_{2} \mathrm{O}_{\mathrm{g}} \mathrm{g}^{-1} \mathrm{MS}$ e aumentou para $1,336 \mathrm{~g} \mathrm{H}_{2} \mathrm{O}_{\mathrm{g}} \mathrm{g}^{-1} \mathrm{MS}$ nas sementes germinadas ( $240 \mathrm{~h}$ ), ou seja, elas absorveram mais de $32 \%$ do seu conteúdo inicial. Contudo, considerando a umidade em função da massa fresca, o conteúdo aumentou cerca de 7\%, o que parece pouco relevante, embora seja estatisticamente significativo (Tab. 2). Essa absorção de água pode ter contribuído para a expansão celular associada à germinação. Segundo De Castro \& Hilhorst (2004), o alongamento das células da radícula inicia-se para um conteúdo de água em torno de $55 \%$ e a sua protrusão ocorre a cerca de $60 \%$, embora o modelo tenha sido elaborado para sementes ortodoxas com padrão trifásico de germinação. Provavelmente, este limiar também se aplica para a espécie estudada no presente trabalho. Em estudos de armazenamento de sementes de E. pyriformis, observou-se germinação dentro das embalagens, indicando que havia umidade suficiente para induzir o processo (Justo et al., dados não publicados).

A partir dos resultados observados conclui-se que eixo embrionário das sementes de E. pyriformis é diferenciado, as células são ricas em grãos de amido e o pólo embrionário localiza-se em uma das extremidades da rafe. A secagem e o envelhecimento durante o armazenamento promoveram danos ultraestruturais significativos, devendo-se, portanto, evitar a secagem e o armazenamento prolongado destas sementes antes da semeadura. O ganho de água que precede a germinação é pequeno, mas significativo para o desencadeamento do processo.
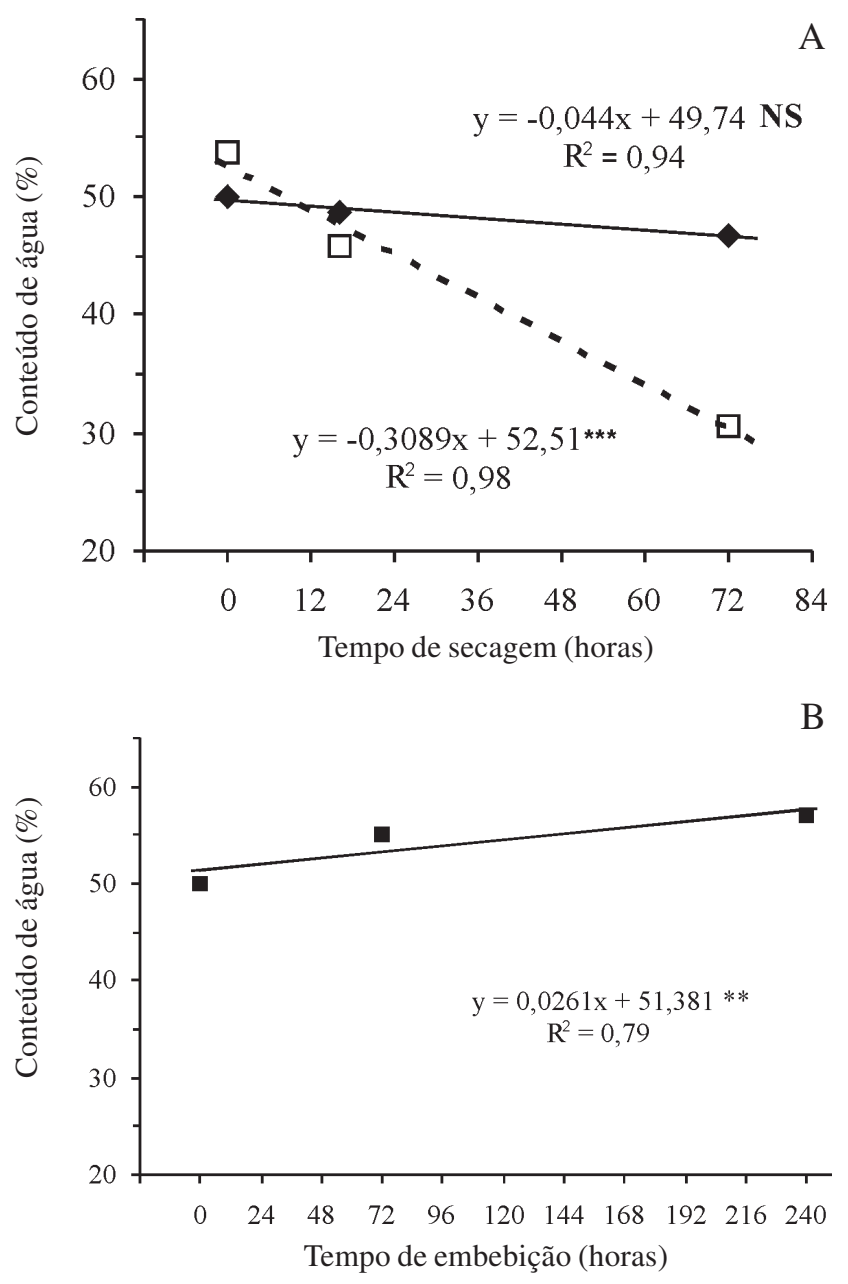

Figura 6. Regressão linear da variação do conteúdo de água das sementes de Eugenia pyriformis Camb. submetidas a diferentes tratamentos. A. Secagem à temperatura de $20^{\circ} \mathrm{C}$ e $35^{\circ} \mathrm{C}$. B. Embebição a $25^{\circ} \mathrm{C}$ em papel Germitest ${ }^{\circledR}$. O teor de água foi determinado em estufa a $105^{\circ} \mathrm{C}$ (Brasil 1992). $\mathrm{NS}=$ não significativo, $* *=$ significativo a $1 \%$ de probabilidade, $* * *=$ significativo a $0,1 \%$ de probabilidade. temperatura de secagem $\left({ }^{\circ} \mathrm{C}\right): \bullet=20 ; \square=35$.

\section{Agradecimentos}

À Universidade Federal de Mato Grosso pela liberação para capacitação da primeira autora, à CAPES pela concessão da bolsa de estudos (PICDT) e aos revisores pelas proveitosas sugestões.

\section{Referências bibliográficas}

Alves, E. 2004. Curso introdutório de microscopia eletrônica de varredura. Lavras, Universidade Federal de Lavras. Andrade, A.C.S.; Cunha, R.; Souza, A.F.; Reis, R.B. \& Almeida, K.J. 2003. Physiological and morphological aspects of seed viability of a neotropical savanna tree, Eugenia dysenterica DC. Seed Science and Technology 31(1): 125-137. 
Andrade, R.N.B. \& Ferreira, A.G. 2000. Germinação e armazenamento de sementes de uvaia (Eugenia pyriformis Camb.) - Myrtaceae. Revista Brasileira de Sementes 22(2): 118-125.

Anjos, A.M.G. \& Ferraz, I.D.K. 1999. Morfologia, germinação e teor de água das sementes de araçá-boi (Eugenia stipitata ssp. sororia). Acta Amazonica 29: 337-348.

Bailly, C. 2004. Active oxygen species and antioxidants in seed biology. Seed Science Research 14: 93-107.

Barroso, G.M. 2002. Sistemática de angiospermas do Brasil. 2. ed. Viçosa, Universidade Federal de Viçosa.

Berjak, P.; Dini, M. \& Pammenter, N.W. 1984. Possible mechanisms underlying the differing dehydration responses in recalcitrant and orthodox seeds: desiccation-associated subcellular changes in propagules of Avicennia marina. Seed Science and Technology 12: 365-384.

Berjak, P. \& Pammenter, N.W. 2000. What ultrastructure has told us about recalcitrant seeds. Revista Brasileira de Fisiologia Vegetal 12(número especial): 22-55.

Brasil, Ministério da Agricultura, do Abastecimento e da Reforma Agrária. 1992. Regras para análise de sementes. Brasília, SNAD/DNDV/CLAV.

Bulow, J.F.W.; Carmona, R. \& Parente, T.V. 1994. Armazenamento e tratamento de sementes de pitangavermelha-do-cerrado (Eugenia calycina). Pesquisa Agropecuária Brasileira 29(6): 961-970.

Chandel, K.P.S.; Chaudhury, R.; Radhamani, J. \& Malik, S.K. 1995. Desiccation and freezing sensitivity in recalcitrant seeds of tea, cocoa and jackfruit. Annals of Botany 76(5): 443-450.

Costa, I.R. 2004. Estudos cromossômicos em espécies de Myrtaceae Juss. no sudeste do Brasil. Campinas, Unicamp. Dissertação Mestrado. Disponível on line: Biblioteca Digital da Unicamp. (Acesso em: 3/01/2006).

De Castro, R.D. \& Hilhorst, H.W.M. 2004. Embebição e reativação do metabolismo. Pp. 149-162. In: A.G. Ferreira \& F. Borghetti (eds.). Germinação. Do básico ao aplicado. Porto Alegre, Artmed.

Delgado, L.F. Tolerância à dessecação em sementes de espécies brasileiras de Eugenia. São Paulo Instituto de Botânica. (Dissertação de Mestrado). 2006. Disponível on line em: http:/www.ibot.sp.gov.br/ teses/ liliana2006.pdf. (Acesso em: 10/08/2006).

Donadio, L.C.; Môro, F.V. \& Servidone, A.A. 2002. Frutas Brasileiras. Jaboticabal, Novos Talentos.

Fahn, A. 1982. Anatomía Vegetal. $3^{\text {rd }}$. Madrid, Pirámide.

Farrant, J.M.; Pammenter, N.W. \& Berjak, P. 1986. The increasing desiccation sensitivity of recalcitrant Avicennia marina seeds with storage time. Physiologia Plantarum 67: 291-298.

Ferreira, D.F. 2003. SISVAR, versão 4.6. Lavras, UFLA. Disponível on line em: danielff@ufla.br.

Finch-Savage, W.E.; Hendry, G.A.F. \& Atherton, N.M. 1994. Free radical activity and loss of viability during drying of desiccation-sensitive tree seeds. Proceedings of the Royal Society of Edinburgh 102B: 257-260.
Franzon, R.C.; Raseira, M.C.B. \& Wagner Júnior, A. 2004. Fenologia da floração e maturação dos frutos da uvalheira (Eugenia pyriformis Camb.), em Pelotas, RS. Pp. 397-402. In: Resumos do II Simpósio Nacional do Morango e do 10 Encontro de Pequenas Frutas e Frutas Nativas do Mercosul. Pelotas, 2004. L.E.C. Antunes; M.C.B. Raseira; E. D. Gonçalves; R. Trevisan (eds.). Pelotas, RS: Embrapa Clima Temperado, Documentos 123, jun. 2004. (Embrapa Clima Temperado. Documentos, 123). Disponível on-line em: www.cpact.embrapa.br. (Acesso em: 10/12/2005).

Goldbach, H. 1979. Imbibed storage of Melicoccus bijugatus and Eugenia brasiliensis (E. dombeyi) usisng abscisic acid as a germination inhibitor. Seed Science and Technology 7: 403-406.

Hendry, G.A.F. 1993. Oxygen, free radical processes and seed longevity. Seed Science Research 3: 141-153.

Hendry, G.A.F.; Finch-Savage, W.E.; Thorpe, P.C.; Atherton, N.M.; Buckland, S.M.; Nilsson, K.A. \& Seel, W.A. 1992. Free radical processes and loss of viability during desiccation in the recalcitrant species Quercus robur L. New Phytologist 122: 273-279.

Karnovisky, M.J. 1065. A formaldehyde-glutaraldehyde fixative of high osmolality for use in electron microscopy. Journal of Cell Biology 27: 137A-138A.

Kranner, I. \& Birtic, S. 2005. A modulating role for antioxidants in desiccation tolerance. Integrative and Comparative Biology 45: 734-740.

Landrum, L.R. \& Stevenson, D. 1986. Variability of embryos in subtribe Myrtinae (Myrtaceae). Systematic Botany 11(1): 155-162.

Leal, M.A.G. 2005. Fórum do Atelier do Bonsai. Disponível on line em: <http://www.atelierdobonsai.com.br/forum viewtopic.php? $\mathrm{t}=355 \&$ start $=0$ \&postdays $=$ 0\&postorder $=$ asc\&highlight (Acesso em: 14/01/2006).

Leprince, O.; Deltour, R.; Thorpe, P.C.; Atherton, N.M. \& Hendry, G.A.F. 1990. The role of free radicals and radical processing systems in loss of desiccation tolerance in germinating maize. New Phytologist 116: 573-580.

Lorenzi, H. 2002. Árvores brasileiras. v. 1 e 2. $4^{\mathrm{a}}$ ed. Nova Odessa, Instituto Plantarum.

Lucas, E.J.; Belsham, S.R.; Nic Lughadha, E.M.; Orlovich, D.A.; Sakuragui, C.M.; Chase, M.W. \& Wilson, P.G. 2005. Phylogenetic patterns in the fleshy-fruited Myrtaceaepreliminary molecular evidence. Plant Systematics and Evolution 251: 35-51.

Maluf, A.M.; Bilia, D.A.C. \& Barbedo, C.J. 2003. Drying and storage of Eugenia involucrata DC. seeds. Scientia Agricola 60(3): 471-475.

Modesto, Z.M.M. \& Siqueira, N.J.B. 1981. Botânica. São Paulo, Editora Pedagógica e Universitária.

Niemenak, N.; Rohsius, C.; Elwers, S.; Ndoumou, D.O. \& Lieberei, R. 2006. Comparative study of different cocoa (Theobroma cacao $L$.) clones in terms of their phenolics and anthocyanins contents. Journal of Food Composition and Analysis, no prelo. Disponível on line em: http://www.sciencedirect.com/science. Acesso em: 10/02/2006. 
Pammenter, N.W. \& Berjak, P. 1999. A review of recalcitrant seed physiology in relation to desiccation tolerance mechanisms. Seed Science Research 9: 13-37.

Pammenter, N.W.; Farrant, J.M. \& Berjak, P. 1984. Recalcitrant seeds: short term storage effects in Avicennia marina. (Forsk.) Vierh. may be germination associated. Annals of Botany 54: 843-846.

Prakash, N. 1979. Embryological studies on economic plants. New Zealand Journal of Botany 17: 525-534.

Rice-Evans, C.A.; Miller, N.J. \& Paganga, G. 1996. Structureantioxidant activity relationships of flavonoids and phenolic acids. Free Radical Biology and Medicine 20(7): 933-956.

Rizzini, C.T. 1970. Efeito tegumentar na germinação de Eugenia dysenterica DC. (Myrtaceae). Revista Brasileira de Biologia 30: 381-402.

Salomão, A.N. \& Santos, I.R.I. 2000. Seed tolerance to desiccation of Brazilian fruit trees; a preliminary study. IPGRI Newsletter 7: 27-28.

Santana, D.G. \& Ranal, M.A. 2000. Análise estatística da germinação. Revista Brasileira de Fisiologia Vegetal 12(edição especial): 175-204.

Scalon, S.; Scalon Filho, H. \& Rigoni, M.R. 2004. Armazenamento e germinação de sementes de uvaia Eugenia uvalha Cambess. Ciência e Agrotecnologia 28(6): 1228-1234.

Schmeda-Hirchmann, G.; Theodoluz, C.; Franco, L.; Ferro, E. \& Arias, A.R. 1987. Preliminary pharmacological studies on Eugenia uniflora: xantina oxidase inhibitory activity. Journal of Ethnopharmacology 21: 183-186.
Schmid, R. 1972. A resolution of the Eugenia-Syzygyum controversy (Myrtaceae). American Journal of Botany 59: 423-436.

Silva, C.V.; Bilia, D.A.C.; Maluf, A.M. \& Barbedo, C.J. 2003. Fracionamento e germinação de sementes de uvaia (Eugenia pyriformis Cambesss. - Myrtaceae). Revista Brasileira de Botânica 26(2): 231-221.

Silva, D.B.; Silva, J.A.; Junqueira, N.T.V. \& Andrade, L.R.M. 2001. Frutas do Cerrado. Brasília, Embrapa Informação Tecnológica.

Theodoluz, C.; Franco, L.; Ferro, E. \& Schmeda-Hirchmann, G. 1988. Xanthine oxidase inhibitory activity of Paraguayan Myrtaceae. Journal of Ethnopharmacology 24: 179-183.

Tommasi, F.; Paciolla, C. \& Arrigoni, O. 1999. The ascorbate system in recalcitrant and orthodox seeds. Physiologia Plantarum 105: 193-198.

Van Wyk, A.E. \& Botha, R. 1984. The genus Eugenia (Myrtaceae) in southern Africa: Ontogeny and taxonomic value of the seed. South African Journal of Botany 3(1): 63-80.

Vertucci, C.W. 1989. The effects of low water contents on physiological activities of seeds. Physiologia Plantarum 77: 172-176.

Vertucci, C.W. \& Farrant, J.M. 1995. Acquisition and loss of desiccation tolerance. Pp. 237-271. In: J. Kigel \& G. Galili (eds.). Seed development and germination. New York, Marcel Dekker.

Vertucci, C.W. \& Leopold, A.C. 1984. Bound water in soybean seed and its relation to respiration and imbibitional damage. Plant Physiology 75: 114-117. 